\title{
Nasal septum angiofibroma: a rare condition with an unusual onset
}

\author{
Maria Carla Spinosi ${ }^{1}$, Francesca D’Amico ${ }^{1}$, Chiara Mezzedimi', \\ Cristiana Bellan ${ }^{2}$, Manuela Cirami ${ }^{2}$, llaria Innocenti Paganelli ${ }^{1}$ \\ ${ }^{1}$ ENT Clinic, S.M. alle Scotte University Hospital of Siena, \\ ${ }^{2}$ Institute of Pathologic Anatomy and Histopathology, University of Siena, Siena, Italy
}

\begin{abstract}
J Korean Assoc Oral Maxillofac Surg 2019;45:43-47)
The characteristics of extra-nasopharyngeal angiofibromas tend to be different from angiofibromas of the nasopharynx according to patient gender, patient age, prevalence, affected site, pathogenesis, and clinical and epidemiological features. We report a case of an extra-nasopharyngeal angiofibroma in a 28-year-old man referred to the ENT Clinic for right-sided epistaxis, airflow impairment and nasal swelling. The right nostril was completely occluded works by a reddish-yellow mass that bled easily. The computed tomography scan revealed an "inhomogeneous solid lesion in the nasal fossa". With the patient under general anesthesia, the formation in the anterior portion of the right side of the nasal septum was removed up to its vascular base. Although electrical cauterization efficiently controlled the bleeding, we abraded the sub-perichondral area to prevent further bleeding as well as recurrence. The histological exam report confirmed the diagnosis of angiofibroma. As in our case, epistaxis is commonly the presenting sign of angiofibroma. Yet its onset was peculiar, given that the bleeding started with a low impact trauma. The nasal swelling was also a relevant feature as well as the breathing impairment. Although uncommon, nasal septal angiofibromas should considered in patients with epistaxis.
\end{abstract}

Key words: Angiofibroma, Nasal septum, Epistaxis

[paper submitted 2017. 8. 31 / revised 2017. 11. 28 / accepted 2017. 12. 20]

\section{Introduction}

Angiofibroma is a histologically-benign and locallyaggressive vascular tumor that typically originates from the nasopharynx (NA). It represents $0.05 \%$ of all head and neck neoplasms ${ }^{1}$ and mostly affects adolescent males. Angiofibromas outside the NA, extra-nasopharyngeal angiofibromas (ENAF), most frequently involve the maxilla ${ }^{2}$ but can also be found in the ethmoid, nasal cavities or nasal septum ${ }^{3}$, although these localizations are uncommon. Characteristics of ENAF tend to be quite different from an angiofibroma of the NA, including patient gender ${ }^{4,5}$, patient age ${ }^{2}$, prevalence, affected site, pathogenesis, and clinical and epidemiological

\author{
Maria Carla Spinosi \\ ENT Clinic, S.M. alle Scotte University Hospital of Siena, Viale Bracci 16, \\ 53100 Siena, Italy \\ TEL: +39-0577-585470 FAX: +39-0577-547940 \\ E-mail: mariacarla.spinosi@gmail.com \\ ORCID: https://orcid.org/0000-0002-7492-6565
}

(c) This is an open-access article distributed under the terms of the Creative Commons Attribution Non-Commercial License (http://creativecommons.org/ licenses/by-nc/4.0/), which permits unrestricted non-commercial use, distribution, and reproduction in any medium, provided the original work is properly cited.

Copyright (C) 2019 The Korean Association of Oral and Maxillofacial Surgeons. All rights reserved. features $^{6,7}$, and some authors classify ENAF as a different disease $^{8,9}$. Although management of ENAF is not fully codified, imaging, endoscopy, and clinical features are extremely helpful in diagnosis, and embolization has been used in selected cases $^{10}$.

Since the clinical characteristics of ENAF do not conform with those of the more common NA, these tumors could present a diagnostic challenge ${ }^{11}$. More often than not, epistaxis is the presenting sign', but nasal obstruction, pain, hyposmia and progressive swelling of the nose have also been report$\mathrm{ed}^{7}$.

The computed tomography (CT) scan has been considered the preferred radiological exam for many years ${ }^{12-14}$, and magnetic resonance imaging (MRI) is used to determine the tumor site and extension ${ }^{11}$.

Various therapeutic approaches have been proposed, including radiotherapy $(\mathrm{RT})^{8}$, endoscopic surgery, and preoperative embolization. The majority of arteriovenous malformations, including ENAF, are treated with embolization of the hypervascular lesion during arteriography combined with surgical treatment ${ }^{4,15}$. Surgery is generally considered the best treatment modality ${ }^{11,16}$. However, vascular intranasal 
tumors might be difficult to treat, and selective embolization is recommended in cases of tumors reaching a large volume, which tends to make the procedure complex and bloody ${ }^{10}$.

Under general anesthesia an endoscopic and endonasal removal should be attempted ${ }^{18}$, although excessive bleeding could require an external incision ${ }^{10,19}$. Additionally, electrical cauterization might not suffice, thus an abrasion from the submucosal to the sub-perichondral area should be performed $^{20}$. Recurrence of ENAF is rare ${ }^{10,11}$.

\section{Case Report}

A 28-year-old man was referred from the emergency room (ER) of the S.M. alle Scotte University Hospital of Siena to the ENT Clinic for profuse nasal bleeding from the right nostril in February 2017.

After suction and removal of several blood clots, physical examination revealed a right-sided lobulated mass in the right nasal fossa. The patient reported that fifteen days prior to presentation, he dove into a pool and afterwards suffered airflow impairment and recurrent dripping of blood from that nostril. He could not recall previous episodes of epistaxis, not even as a child, and he did not complain about nasal pain, neck swelling or hearing impairment.

The patient's clinical history was negative for recent illnesses and familiar pathologies, drugs and medication consumption (neither habitually nor in the previous month), cocaine use, smoking and exposure to nasal irritants. Moreover, he was in good physical shape; he practiced swimming twice a week, and he was a blood donor. According to the standard procedure to donate in Italy, he had recently (3 months earlier) submitted to blood testing and electrocardiography.

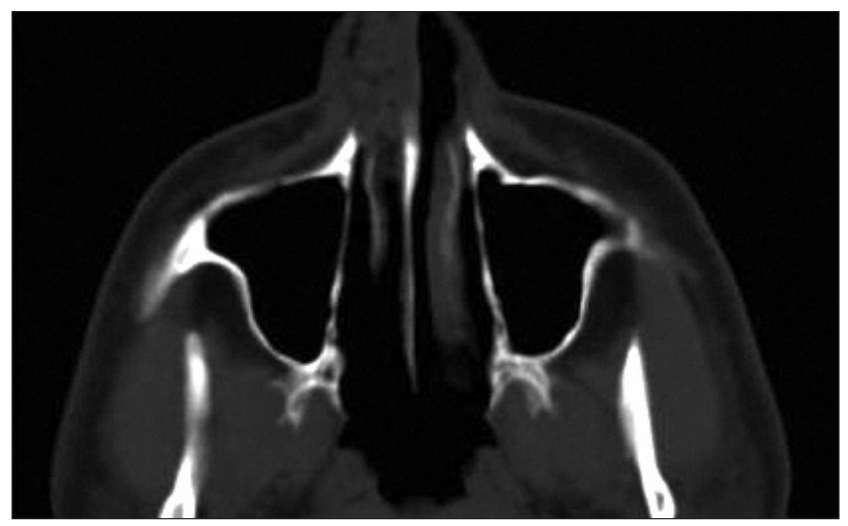

Fig. 1. Computed tomography scan of the nasal angiofibroma. Maria Carla Spinosi et al: Nasal septum angiofibroma: a rare condition with an umusual onset. J Korean Assoc Oral Maxillofac Surg 2019
No anemia, alterations of blood coagulation or other anomalies had been detected. His blood tests, repeated in the ER, showed a slight impairment of hemoglobin and hematocrit, although this was not relevant.

After spontaneous interruption of bleeding, the fibroscopic examination was conducted through the left nostril only (to avoid further bleeding from the mass) and did not reveal any anomalies in the NA or the larynx. No neck masses could be detected through palpation.

A CT scan of the head and neck was prescribed (Fig. 1), and the radiologist reported an "inhomogeneous solid lesion (post-traumatic scab? polypoid formation?) in the right nasal fossa to be further studied with MRI with contrast...".

An absorbable gauze was delicately put into the right nostril, and an MRI scan was scheduled for five weeks, the first available date.

Three days following his initial presentation and examination, the patient was re-evaluated by an otolaryngologists. The patient did not report any further bleeding, and the absorbable gauze was removed. The physical and endoscopic examination (this time also conducted through the right nostril) revealed the mass had considerably diminished in size (less than $0.5 \mathrm{~cm}$ ), and no active bleeding points were visible.

Despite the otolaryngologist's recommendation, the patient firmly refused further treatment or examination. Therefore, he was dismissed but agreed to return for another appointment the following week.

The night before the second planned follow-up, the patient returned for profuse bleeding from the right nostril accompanied with complete blockage of airflow, right-sided nasal swelling, anxiety and panic. Upon physical examination, the right nostril was completely occluded works by a reddishyellow mass that bled easily.(Fig. 2, 3) We admitted him to our clinic and administered mild sedatives, antibiotics, and tranexamic acid. Fortunately, the nasal bleeding stopped and the patient calmed down. Surgery was planned for the fol-

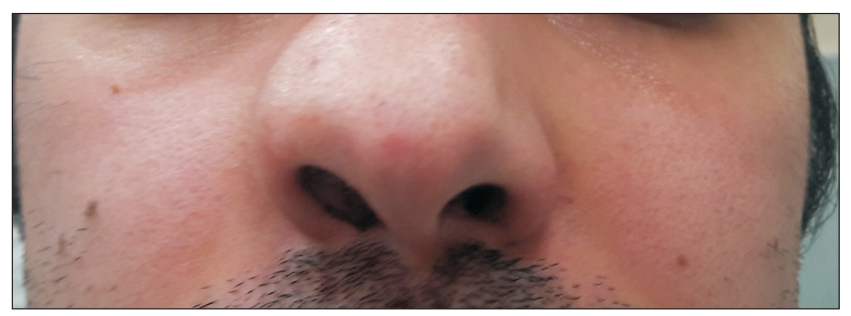

Fig. 2. Angiofibroma; frontal view.

Maria Carla Spinosi et al: Nasal septum angiofibroma: a rare condition with an unusual onset .J Korean Assoc Oral Maxillofac Surg 2019 
lowing morning. The MRI scan could not be done due to the short notice.

With the patient under general anesthesia, the formation situated in the anterior portion of the right side of the nasal septum was removed up to its vascular base and sent for a histological examination. Although electrical cauterization efficiently controlled the bleeding (Fig. 4, 5), we decided to perform an abrasion of the sub-perichondral area to prevent further bleeding and recurrence. Finally, through a $0^{\circ}$ and a $30^{\circ}$ endoscope, we performed an inspection of the nasal cavities, identifying a mild swelling in the posterior wall of the NA. Thus, the tissue was biopsied, and the specimen was sent for the histological examination as well.

Two 8-cm-long sponges were applied in the nasal fossa. The patient's postoperative recovery was uneventful, and he was discharged without any complications the following day. The nasal pack was removed within three days of the intervention, and the nasal inspection revealed normal postopera-

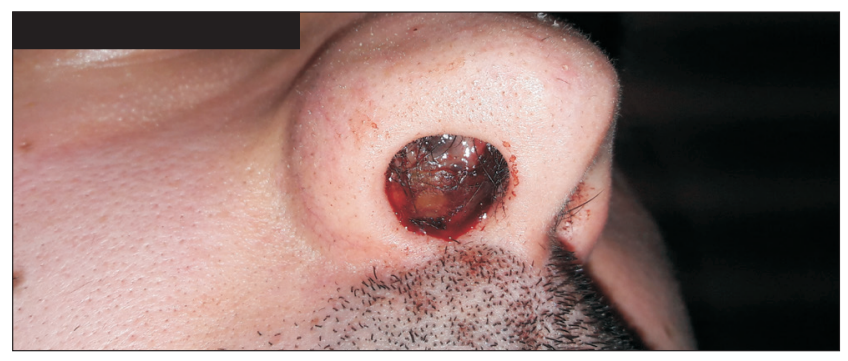

Fig. 3. Angiofibroma; inferolateral view.

Maria Carla Spinosi et al: Nasal septum angiofibroma: a rare condition with an unusual onset . J Korean Assoc Oral Maxillofac Surg 2019

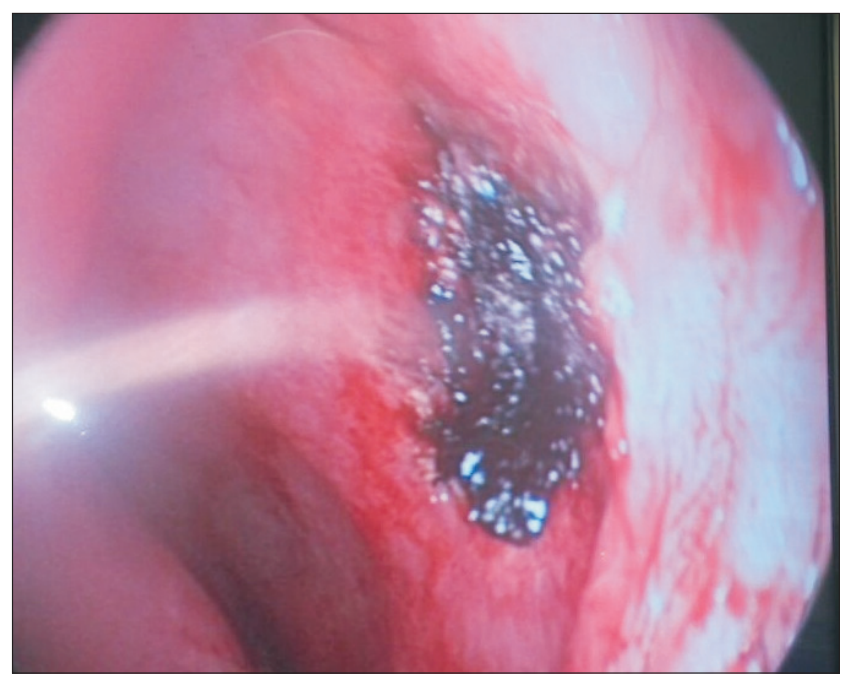

Fig. 4. Endoscopic view of the nasal fossa after surgical removal of the angiofibroma.

Maria Carla Spinosi et al: Nasal septum angiofibroma: a rare condition with an unusual onset. J Korean Assoc Oral Maxillofac Surg 2019 tive healing.

The histological exam report read "hyperplasia of the

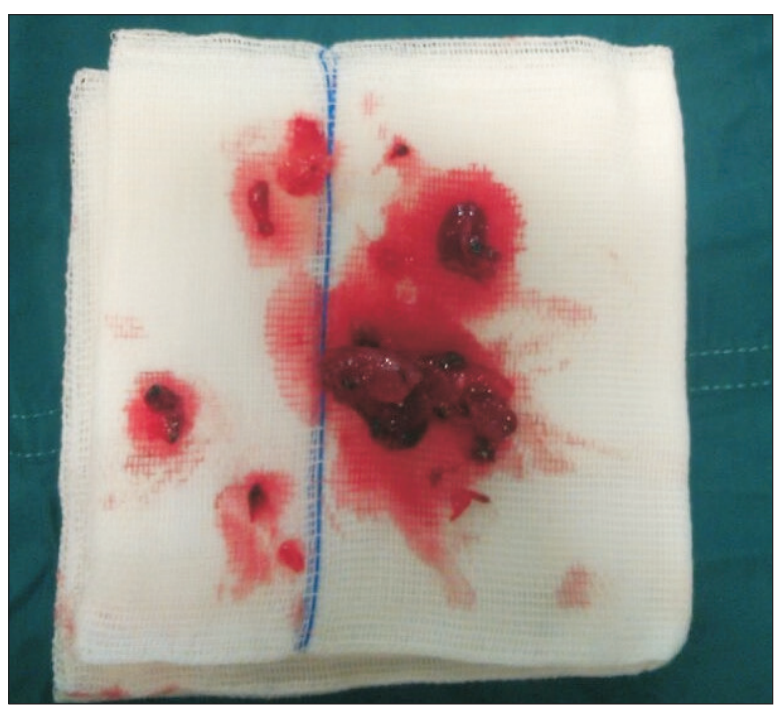

Fig. 5. Specimen collection.

Maria Carla Spinosi et al: Nasal septum angiofibroma: a rare condition with an unusual onset. J Korean Assoc Oral Maxillofac Surg 2019

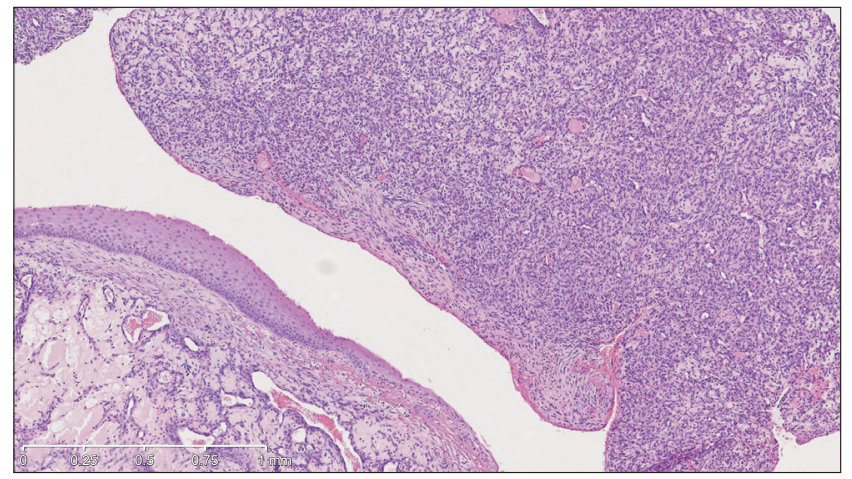

Fig. 6. Histologic sample (H\&E staining, $\times 5)$.

Maria Carla Spinosi et al: Nasal septum angiofibroma: a rare condition with an unusual onset. J Korean Assoc Oral Maxillofac Surg 2019

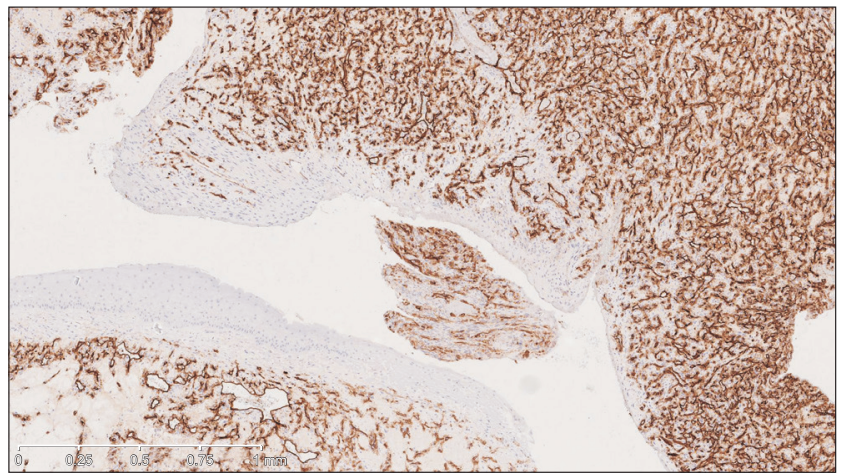

Fig. 7. Histological sample (CD34 staining, $\times 5)$.

Maria Carla Spinosi et al: Nasal septum angiofibroma: a rare condition with an unusual onset .J Korean Assoc Oral Maxillofac Surg 2019 
lymphatic tissue with active germinative centers" for the nasopharyngeal tissue, and "angiofibroma" (Fig. 6, 7) for the nasal septum mass.

The patient returned for three follow-up appointments at two weeks postoperative, one month later and, finally, six months after surgery. Until now, no recurrence or other nasal anomalies have been visible.

\section{Discussion}

Since the characteristics of an angiofibroma originating from the nasal septum completely differ from the characteristics of an angiofibroma localized in the NA and because of our experience, we agree with Tasca and Compadretti ${ }^{11}$ that the different designation "extra-nasopharyngeal angiofibroma" should be used to correctly identify these lesions.

The nasal septum is an extremely rare site for ENAF, and, to date, there are less than 30 reported cases in the scientific literature ${ }^{7}$, beginning with Hiraide and Matsubara ${ }^{17}$ in 1984.

As commonly occurs, epistaxis was the presenting sign of the angiofibroma in our case. However, the onset was unusual, because the bleeding was caused by a dive in a swimming pool, a low impact trauma. In addition, the patient in this case had a significant amount of anxiety from the nasal swelling and breathing impairment.

Despite being uncommon, nasal septal angiofibromas should be considered during the evaluation and treatment of epistaxis. Although the histological examination confirms the diagnosis, ENAF can be effectively managed in an early timeframe with an objective examination through the fiberscope, the CT scan, as well as carefully collecting the anamnesis.

In addition, the MRI provides further preoperative information regarding the necessity of embolization to reduce the risk of bleeding during the procedure. However, we decided not to wait for the scan in our case since the first available appointment was one month later, and we proceeded with surgery as soon as possible for multiple indications. First of all, we did not want the lesion to grow, as vascular tumors are more difficult to treat if they reach a large volume and extend towards adjacent areas. Secondly, we did not want to inconvenience such a young and active patient with physical restrictions (by avoiding sport and exertion) and potentially dangerous and uncomfortable conditions (anemia, airflow impairment, nasal blockage) for a long period of time. Last but not least, we intended to prevent further psychological distress and other episodes of panic attacks which impeded his cooperation during the bleeding episodes and may cause his refusal to undergo further examinations or procedures, a situation that occurred during the first follow-up.

\section{ORCID}

Maria Carla Spinosi, https://orcid.org/0000-0002-74926565

Francesca D'Amico, https://orcid.org/0000-0003-44130686

Chiara Mezzedimi, https://orcid.org/0000-0003-2000-7392

Cristiana Bellan, https://orcid.org/0000-0001-6119-9007

Manuela Cirami, https://orcid.org/0000-0003-2300-3135

Ilaria Innocenti Paganelli, https://orcid.org/0000-0002$3242-6327$

\section{Authors' Contributions}

M.C.S. participated in data collection and wrote the manuscript. F.D.A. partecipated in the data collection and drafted the manuscript. C.M. and I.I.P. participated in the study design and coordination and helped to draft the manuscript. C.B. and M.C. contributed to the data collection and the histopatological analysis. All authors read and approved the final manuscript.

\section{Consent for Publishing Photographs}

Written informed consent was obtained from the patient for publication of this article and accompanying images.

\section{Conflict of Interest}

No potential conflict of interest relevant to this article was reported.

\section{References}

1. Barnes L, Brandwein M, Som PM. Diseases of the nasal cavity, paranasal sinuses, and nasopharynx. In: Barnes L, ed. Surgical pathology of the head and neck. New York: Marcel Dekker; 2001:440516.

2. Doğan S, Yazici H, Baygit Y, Metin M, Soy FK. Extranasopharyngeal angiofibroma of the nasal septum: a rare clinical entity. $\mathrm{J}$ Craniofac Surg 2013;24:e390-3.

3. Windfuhr JP, Remmert S. Extranasopharyngeal angiofibroma: etiology, incidence and management. Acta Otolaryngol 2004;124:8809.

4. Sarpa JR, Novelly NJ. Extranasopharyngeal angiofibroma. Otolaryngol Head Neck Surg 1989;101:693-7. 
5. Ewe S, Dayana F, Fadzilah FM, Gendeh BS. Nasal septal angiofibroma in a post-menopausal woman: a rare entity. J Clin Diagn Res 2015;9:MD03-5.

6. Windfuhr JP, Remmert S. [Extranasopharyngeal angiofibroma of the nasal cavity and paranasal sinuses]. Laryngorhinootologie 2004;83:308-16. German.

7. Perić A, Sotirović J, Cerović S, Zivić L. Immunohistochemistry in diagnosis of extranasopharyngeal angiofibroma originating from nasal cavity: case presentation and review of the literature. Acta Medica (Hradec Kralove) 2013;56:133-41.

8. Correia FG, Simões JC, Mendes-Neto JA, Seixas-Alves MT, Gregório LC, Kosugi EM. Extranasopharyngeal angiofibroma of the nasal septum--uncommon presentation of a rare disease. Braz $\mathrm{J}$ Otorhinolaryngol 2013;79:646.

9. Garcia-Rodriguez L, Rudman K, Cogbill CH, Loehrl T, Poetker DM. Nasal septal angiofibroma, a subclass of extranasopharyngeal angiofibroma. Am J Otolaryngol 2012;33:473-6.

10. Fassih M, Taali L, Abada A, Rouadi S, Roubal M, Mahtar M, et al. [Vascular tumors of the nasal cavities: a retrospective study of 10 cases]. Rev Laryngol Otol Rhinol (Bord) 2012;133:87-92. French.

11. Tasca I, Compadretti GC. Extranasopharyngeal angiofibroma of nasal septum. A controversial entity. Acta Otorhinolaryngol Ital 2008;28:312-4

12. Thomas RL. Computed tomography in the assessment of patients with juvenile post-nasal angiofibroma. J Otolaryngol 1980;9:33441.

13. Briant TD, Fitzpatrick PJ, Berman J. Nasopharyngeal angiofibroma: a twenty year study. Laryngoscope 1978;88:1247-51.

14. Hamdan AL, Moukarbel RV, Kattan M, Natout M. Angiofibroma of the nasal septum. Middle East J Anaesthesiol 2012;21:653-5.

15. Son YH, Baik SK, Kang MS, Kim YD. Recurrent arteriovenous malformation on palate after embolization combined surgical resection: preoperative magnetic resonance features and intraoperative angiographic findings. J Korean Assoc Oral Maxillofac Surg 2015;41:346-51.

16. Atmaca S, Bayraktar C, Yildı L. Extranasopharyngeal angiofibroma of the posterior nasal septum: a rare clinical entity. Kulak Burun Bogaz Ihtis Derg 2013;23:295-8.

17. Hiraide F, Matsubara H. Juvenile nasal angiofibroma: a case report. Arch Otorhinolaryngol 1984;239:235-41.

18. Uyar M, Turanli M, Pak I, Bakir S, Osma U. Extranasopharyngeal angiofibroma originating from the nasal septum: a case report. $\mathrm{Ku}-$ lak Burun Bogaz Ihtis Derg 2009;19:41-4.

19. Handa KK, Kumar A, Singh MK, Chhabra AH. Extranasopharyngeal angiofibroma arising from the nasal septum. Int J Pediatr Otorhinolaryngol 2001;58:163-6.

20. Mohamed AA. [Angiofibroma of the nasal fossae: apropos of 12 cases observed in Mali]. Med Trop (Mars) 1994;54:247-8. French. 